\title{
Improving global detection of volcanic eruptions using the Ozone Monitoring Instrument (OMI)
}

\author{
Verity J. B. Flower, Thomas Oommen, and Simon A. Carn \\ Dept. Geological and Mining Engineering and Sciences, Michigan Technological University, 1400 Townsend Dr, \\ Houghton, MI 49931, USA \\ Correspondence to: Verity J. B. Flower (vjbflower@gmail.com)
}

Received: 14 June 2016 - Published in Atmos. Meas. Tech. Discuss.: 4 July 2016

Revised: 29 October 2016 - Accepted: 31 October 2016 - Published: 16 November 2016

\begin{abstract}
Volcanic eruptions pose an ever-present threat to human populations around the globe, but many active volcanoes remain poorly monitored. In regions where groundbased monitoring is present the effects of volcanic eruptions can be moderated through observational alerts to both local populations and service providers, such as air traffic control. However, in regions where volcano monitoring is limited satellite-based remote sensing provides a global data source that can be utilised to provide near-real-time identification of volcanic activity. This paper details a volcanic plume detection method capable of identifying smaller eruptions than is currently feasible, which could potentially be incorporated into automated volcanic alert systems. This method utilises daily, global observations of sulfur dioxide $\left(\mathrm{SO}_{2}\right)$ by the Ozone Monitoring Instrument (OMI) on NASA's Aura satellite. Following identification and classification of known volcanic eruptions in 2005-2009, the $\mathrm{OMI} \mathrm{SO}_{2}$ data, analysed using a logistic regression analysis, permitted the correct classification of volcanic events with an overall accuracy of over $80 \%$. Accurate volcanic plume identification was possible when lower-tropospheric $\mathrm{SO}_{2}$ loading exceeded $\sim 400 \mathrm{t}$. The accuracy and minimal user input requirements of the developed procedure provide a basis for incorporation into automated $\mathrm{SO}_{2}$ alert systems.
\end{abstract}

\section{Introduction}

Volcanic eruptions pose a global hazard due to the potential for emissions to be entrained into the upper atmosphere and transported globally. Emissions from volcanoes can have significant impacts on human health (Delmelle et al., 2002;
Hansell and Oppenheimer, 2004), on the aviation industry (Miller and Casadevall, 1999; Prata, 2009), and on atmospheric radiative transfer as seen following the eruption of Mt Pinatubo (Self et al., 1993). In order to mitigate the possible impacts of volcanic eruptions, timely warning of events is essential. Since the installation of a global network of ground-based monitoring stations is both costly and impractical, satellite-based remote sensing data are currently used to provide the spatial and temporal coverage necessary for near-real-time (NRT) monitoring of volcanic eruption clouds (Brenot et al., 2014). Existing volcanic cloud detection techniques employ a threshold approach to identify volcanic eruptions, but this can limit their capabilities with respect to smaller events. The following work outlines a method to distinguish smaller volcanic plumes through the implementation of a background correction factor. The Ozone Monitoring Instrument (OMI), launched on NASA's Aura satellite in July 2004, provides near-global daily monitoring of multiple atmospheric trace gases with absorption features in the ultraviolet (UV) spectral band. OMI was designed to supersede the Total Ozone Monitoring Spectrometer (TOMS) instrument and provide higher-spatial-resolution data than were previously available. Strong absorption bands in the UV allow sulfur dioxide $\left(\mathrm{SO}_{2}\right)$ to be discerned by instruments designed to measure ozone (Krueger, 1983). The capability of satellitebased volcanic $\mathrm{SO}_{2}$ detection was first demonstrated following the eruption of El Chichón in 1982 (Krueger, 1983), leading to the implementation of satellite-based UV measurements as a volcano monitoring tool (Schneider et al., 1999; Krueger et al., 2008; Carn et al., 2016). The low spatial resolution of the TOMS instruments precluded the measurement of $\mathrm{SO}_{2}$ in small volcanic eruptions (Carn et al., 2003). OMI's 
higher spatial resolution $(13 \times 24 \mathrm{~km}$ at nadir $)$ permits detection of smaller eruptions and passive volcanic degassing of $\mathrm{SO}_{2}$, whilst providing daily, global coverage (Krotkov et al., 2006; Carn et al., 2013, 2016). This work utilises the continuous global coverage of OMI to identify and automatically classify volcanic eruptions based on common characteristics established through the use of statistical modelling.

\section{Existing alert systems}

The Support to Aviation Control Service (SACS) is one operational alert system currently used to detect $\mathrm{SO}_{2}$ and ash emitted from volcanoes (Brenot et al., 2012). This service provides NRT alerts of anomalously high $\mathrm{SO}_{2}$ amounts and ash indices recorded by four UV instruments: OMI, the Global Ozone Monitoring Experiment-2 (GOME-2; flown on board two meteorological satellites: MetOp-A and MetOpB), and the Ozone Mapping and Profiler Suite (OMPS). Three infrared (IR) instruments are also used: the Atmospheric Infrared Sounder (AIRS) and Infrared Atmospheric Sounding Interferometer (IASI; also flown on the MetOp-A and -B platforms). The method of $\mathrm{SO}_{2}$ alert generation used by SACS (Brenot et al., 2014; http://sacs.aeronomie.be/info/ index.php) involves the initial identification of an anomalously high $\mathrm{SO}_{2}$ column amount ( $\left.>2 \mathrm{DU}\right)$. When a pixel is flagged, the area is analysed in greater detail, and an alert is only generated if more than half of the neighbouring pixels also display high $\mathrm{SO}_{2}$ values ( $>2 \mathrm{DU}$ ). The technique developed by Brenot et al. (2014) is subject to certain limitations when utilising UV data, including the systematic noise in the data leading to false alerts and the restriction of retrievals to those that assume a $\mathrm{SO}_{2}$ plume altitude in the lower stratosphere (STL). Therefore, in the development of an algorithm based on OMI data we aim to account for variable background $\mathrm{SO}_{2}$ levels and systematic noise. Additionally, $\mathrm{SO}_{2}$ retrievals representing a lower plume altitude are used, in an attempt to resolve plumes with lower $\mathrm{SO}_{2}$ amounts, lower injection altitude, and more diffuse characteristics.

\section{Methodology}

To distinguish volcanic events from background $\mathrm{SO}_{2}$ levels, the characteristics of volcanic emissions must be assessed. In this work we implement statistical classification techniques such as logistic regression to isolate observed variations in volcanic $\mathrm{SO}_{2}$ plumes compared to ambient $\mathrm{SO}_{2}$ levels. The use of statistical modelling also facilitates the review of misclassified events, providing some insight into the limitations of the detection algorithm. The aim of this work is to distinguish volcanic events from control samples with a binary classification algorithm and identify the strengths and weaknesses of the resulting methodology. To develop a model and identify characteristics specific to volcanic plumes, three datasets must be compiled. Firstly, a database of emissions corresponding to known volcanic eruptions must be ob- tained, with a complimentary dataset incorporating measurements collected during known inactive periods against which to compare volcanic events. These two elements are used to train the statistical models developed and establish whether volcanic events can be distinguished from non-volcanic ones. The final dataset is a collection of volcanic and non-volcanic events not used to train the original model, against which the efficacy of the model can be tested. The following section details the data collection and statistical applications used.

\subsection{Satellite data}

For this analysis we use OMI Level 2 total column $\mathrm{SO}_{2}$ (OMSO2) data, which are publicly available from NASA Goddard Earth Sciences (GES) Data and Information Services Center (DISC; http://disc.sci.gsfc.nasa.gov/Aura/ data-holdings/OMI/omso2_v003.shtml). These data provide global coverage with a temporal resolution of 1 day at low latitudes and increasing daily observations towards the poles, where measurement swaths overlap. Until June 2016, $\mathrm{OMSO} 2$ data provided volcanic $\mathrm{SO}_{2}$ total column amounts calculated using a linear fit (LF) algorithm (Yang et al., 2007), which are the products used here. Previous works have provided in-depth descriptions of the OMI retrieval algorithms (Carn et al., 2013; Krotkov et al., 2006; McCormick et al., 2013; Yang et al., 2007), which have a proven track record in the assessment of volcanic and anthropogenic emissions, including identification of volcanic plume sources (e.g. Carn et al., 2008, 2013, 2016; McCormick et al., 2012, 2013), volcanic plume tracking (e.g. Carn and Prata 2010; Krotkov et al., 2010; Lopez et al., 2013), and identification of copper smelter emissions (Carn et al., 2007) and other large $\mathrm{SO}_{2}$ emission sources (e.g. Fioletov et al., 2011, 2013).

The $\mathrm{LF}$ algorithm retrieves three $\mathrm{SO}_{2}$ column amounts corresponding to a priori $\mathrm{SO}_{2}$ vertical profiles with centre of mass altitudes (CMAs) of approximately $3 \mathrm{~km}$ (lower troposphere; TRL), $8 \mathrm{~km}$ (mid-troposphere; TRM), and $17 \mathrm{~km}$ (STL). These altitudes are based upon atmospheric pressure levels and therefore can display slight variations depending upon the local temperature profile (Carn et al., 2013). In order to obtain an accurate estimation of the $\mathrm{SO}_{2}$ column amount, the appropriate $\mathrm{SO}_{2}$ retrieval must be selected based upon the known or inferred injection altitude of the volcanic plume (Yang et al., 2007), which can be poorly constrained particularly in remote regions with minimal or no monitoring capabilities. Differences between the altitude assumed in the LF algorithm and the true altitude of the plume can lead to errors of up to $20 \%$, provided the assumption is approximately correct (Yang et al., 2007). Since our aim is to develop an algorithm capable of detecting volcanic eruptions regardless of magnitude, including diffuse $\mathrm{SO}_{2}$ clouds, we use the TRL $\mathrm{SO}_{2}$ product to permit identification of small eruptions confined to the lower troposphere. The use of one retrieval altitude reduces the need for user input or prior knowledge of the injection altitude of the plume but will result in the 
Table 1. Characteristics of the methods incorporated in the development of an automatic classification technique.

\begin{tabular}{llll}
\hline Method & Sample area size & Position & Correction technique \\
\hline $\mathrm{M}_{1}$ & $4^{\circ} \times 4^{\circ}$ & Centred over the volcano & None applied \\
\hline $\mathrm{M}_{2}$ & $2^{\circ} \times 2^{\circ}$ & Centred over the volcano & None applied \\
\hline $\mathrm{M}_{3}$ & $2^{\circ} \times 2^{\circ}$ & Centred over the volcano & $\begin{array}{l}\text { Assumes that the plume is predominantly confined to the } \mathrm{M}_{2} \\
\text { region and utilises the } \mathrm{M}_{1} \text { region to define the background } \mathrm{SO}_{2} \\
\text { level (Eq. 1) }\end{array}$ \\
\hline
\end{tabular}

overestimation of $\mathrm{SO}_{2}$ mass for plumes injected into the mid-troposphere or above. This method is hence sufficient for plume identification and alert purposes but precludes accurate plume mass calculation for some eruptions. $\mathrm{SO}_{2}$ retrievals corresponding to higher altitudes (TRM or STL) not only feature lower background noise but also significantly underestimate $\mathrm{SO}_{2}$ columns in low-altitude volcanic clouds, possibly preventing detection.

OMI data collected since 2008 are influenced by a row anomaly (the OMI row anomaly; ORA) which results in data gaps in particular rows along the OMI measurement swath. Information on the status of this anomaly is provided by the Royal Netherlands Meteorological Institute (http://projects.knmi.nl/omi/research/product/ rowanomaly-background.php). The ORA data gaps combined with the variation in viewing angle produced by the 16-day orbital cycle of the Aura satellite result in varying influence on $\mathrm{OMI} \mathrm{SO}_{2}$ measurements (Flower et al., 2016). Any eruptions identified after the appearance of the ORA were investigated with greater scrutiny and excluded where the effect was significant.

\subsection{Volcanic plume quantification}

As a training dataset for our plume identification technique, we identified 79 volcanic eruptions at 27 different volcanoes (Table 1) using the Volcanoes of the World (VOTW) database curated by the Smithsonian Institution's Global Volcanism Program (GVP; see Global Volcanism Program, 2013). Note that, as a result of the way in which eruptions are defined in the VOTW database, several of the eruptions listed in Table 1 actually correspond to the onset of extended periods of volcanic activity, rather than discrete eruptions. For each identified eruption, total $\mathrm{SO}_{2}$ mass detected by OMI was obtained for the registered day of the eruptive event (or the start of the period of unrest) with the preceding and subsequent days analysed where no corresponding plume could be identified on the reported day of eruption. This allowance accounts for any inaccuracies in the assigned eruption date and allows for the identification of eruption plumes generated after the Aura overpass time ( $\sim 13: 45$ local time) resulting in a delay in detection. Identification and quantification of volcanic $\mathrm{SO}_{2}$ emissions is complicated by the presence of variable biases and noise levels in the data. These varia-

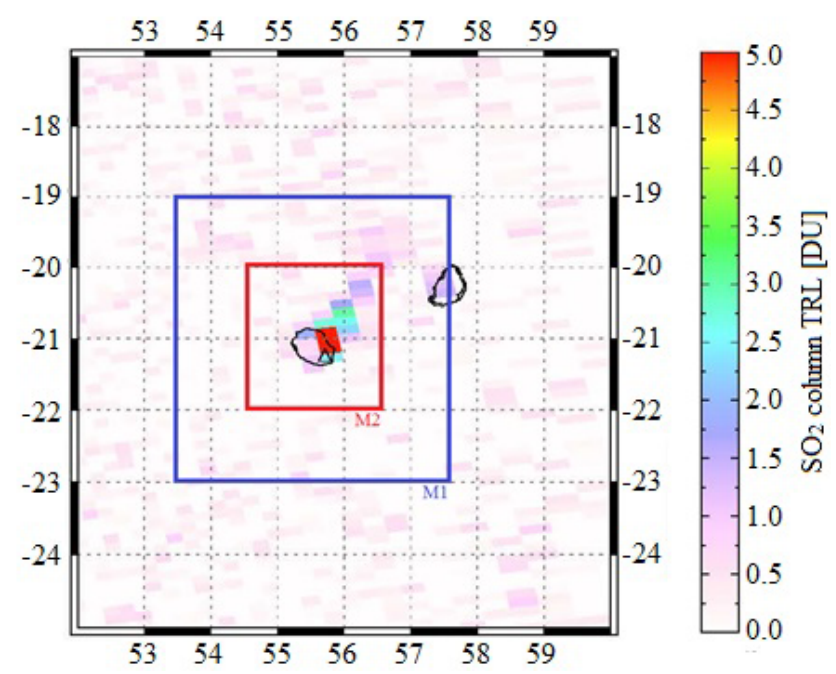

Figure 1. Analysis regions for method $1\left(\mathrm{M}_{1}\right)$ and method $2\left(\mathrm{M}_{2}\right)$ for an $\mathrm{SO}_{2}$ plume detected by OMI at Piton de la Fournaise, Réunion, on 24 February 2010.

tions are influenced by several factors, including the latitude of the volcano, time of year, proximity to pollution sources, and the presence of meteorological clouds (Krotkov et al., 2006; Yang et al., 2007).

In our analysis, three methods $\left(\mathrm{M}_{1}, \mathrm{M}_{2}\right.$, and $\mathrm{M}_{3}$; Table 1) were used to quantify the $\mathrm{SO}_{2}$ loading detected at each location, with the goal of distinguishing volcanic $\mathrm{SO}_{2}$ from background noise. The procedures were developed with the intention of allowing the calculation of volcanic $\mathrm{SO}_{2}$ loading with minimal user input, reducing the possible effects of human error in the classification of what constitutes the bounds of an identified plume.

Method $1\left(\mathrm{M}_{1}\right)$ and method $2\left(\mathrm{M}_{2}\right)$ differ only in the geographic extent over which $\mathrm{OMI} \mathrm{SO}_{2}$ columns are integrated to obtain total $\mathrm{SO}_{2}$ mass (Fig. 1). For each eruption analysed, $\mathrm{M}_{1}$ calculates integrated $\mathrm{SO}_{2}$ mass in a $4^{\circ} \times 4^{\circ}$ box centred over the volcano location (thus capturing plumes regardless of wind direction). The $4^{\circ} \times 4^{\circ}$ box encompasses an area which captures most small-moderate volcanic plumes with few instances of dispersion of emissions outside the region; however, this relatively large sample area also potentially includes greater background noise, particularly where other 
nearby volcanoes are also active. Regions with increased background $\mathrm{SO}_{2}$ concentrations from multiple sources would result in a higher number of false alerts. As an alternative to $\mathrm{M}_{1}, \mathrm{M}_{2}$ uses a $2^{\circ} \times 2^{\circ}$ region which, whilst more susceptible to possible plume dispersion beyond the defined limits, is less influenced by contamination (Fig. 1). Manual inspection indicated that plume dispersion beyond the defined geographic limits was only an issue for the largest eruptions in Table 2. Figure 1 shows an example of a small volcanic $\mathrm{SO}_{2}$ plume at Piton de la Fournaise volcano (Réunion); here, the $\mathrm{M}_{2}$ region captures most of the $\mathrm{SO}_{2}$ plume that is visually apparent, only excluding some very diffuse $\mathrm{SO}_{2}$ further downwind that is included in the $\mathrm{M}_{1}$ region.

A third method $\left(\mathrm{M}_{3}\right)$ was developed in an attempt to intrinsically account for the variable noise levels in $\mathrm{SO}_{2}$ data collected in different geographic regions (Carn et al., 2013). We posit that in order to effectively develop a global volcanic plume detection methodology without a significant number of false alerts a background noise correction may be necessary. Our technique is analogous to contextual thermal infrared (TIR) anomaly detection procedures used at active volcanoes, where a background radiance value is calculated as a reference against which anomalously high radiance values can be compared (e.g. Wright et al., 2002; Murphy et al., 2011). In the $\mathrm{M}_{3}$ method, the $2^{\circ} \times 2^{\circ}$ region $\left(\mathrm{M}_{2}\right)$ is considered the active emission region with a background $\mathrm{SO}_{2}$ offset value derived from the total $\mathrm{SO}_{2}$ mass in the $4^{\circ} \times 4^{\circ} \mathrm{M}_{1}$ region (Eq. 1).

$\mathrm{M}_{3}=\mathrm{M}_{2}-\frac{\mathrm{M}_{1}-\mathrm{M}_{2}}{3}$

Classification based on a latitudinal range leads to variations in the physical dimensions of the analysis region depending upon the latitude of the volcano. The maximum such variation in this analysis would occur between equatorial volcanoes and those located in Kamchatka and Alaska, equating to 2.8 and $1.4 \mathrm{~km}$ in the north-south dimensions of the $\mathrm{M}_{1}$ and $\mathrm{M}_{2}$ regions respectively. This equates to the loss of less than one pixel at the furthest extent of the analysis region and is not likely to influence the resulting analyses. In contrast the variation in the longitudinal dimensions equates to a $\sim 35 \%$ decrease in the east-west dimensions of high-latitude regions relative to the Equator. The high-latitude samples analysed here will be investigated to identify whether this variation in sample size influenced the sample classification techniques employed.

Eruptive events that post-date the appearance of the ORA were manually assessed in order to identify whether the ORA data gap significantly impacted the detection of $\mathrm{SO}_{2}$, such as complete masking of the plume in extreme cases (Flower et al., 2016). Additional factors impacting the selection of eruptive events are the presence of meteorological clouds, which can effectively mask any volcanic plume at lower altitudes from a satellite-based sensor (Carn et al., 2013; Krotkov et al., 2006), and the seasonal variation in UV radiation at high
Table 2. Test dataset of volcanic eruption dates and control dates (organised alphabetically by volcano).

\begin{tabular}{|c|c|c|c|}
\hline Volcano & Location & Eruption date & Control date \\
\hline \multirow[t]{2}{*}{ Ambrym } & \multirow[t]{2}{*}{ Vanuatu } & $08 / 11 / 2006$ & $31 / 03 / 2005$ \\
\hline & & $23 / 05 / 2008$ & 04/06/2008 \\
\hline \multirow[t]{5}{*}{ Anatahan } & \multirow{5}{*}{$\begin{array}{l}\text { Mariana } \\
\text { Islands }\end{array}$} & 06/01/2005 & $11 / 05 / 2009$ \\
\hline & & $05 / 04 / 2005$ & $16 / 06 / 2006$ \\
\hline & & $17 / 03 / 2006$ & $15 / 01 / 2007$ \\
\hline & & $24 / 02 / 2007$ & $22 / 11 / 2005$ \\
\hline & & $27 / 11 / 2007$ & 29/06/2005 \\
\hline \multirow[t]{9}{*}{ Bagana } & \multirow{9}{*}{$\begin{array}{l}\text { Papua } \\
\text { New Guinea }\end{array}$} & $17 / 03 / 2005$ & $26 / 11 / 2007$ \\
\hline & & $06 / 06 / 2005$ & $14 / 06 / 2008$ \\
\hline & & 09/01/2007 & $25 / 04 / 2005$ \\
\hline & & $10 / 03 / 2007$ & $23 / 10 / 2006$ \\
\hline & & $20 / 05 / 2007$ & 06/11/2006 \\
\hline & & $14 / 07 / 2007$ & 01/07/2009 \\
\hline & & $23 / 08 / 2007$ & $22 / 01 / 2006$ \\
\hline & & $12 / 09 / 2007$ & 26/12/2009 \\
\hline & & 06/10/2007 & 01/03/2009 \\
\hline \multirow[t]{2}{*}{ Bezymianny } & \multirow{2}{*}{$\begin{array}{l}\text { Kamchatka, } \\
\text { Russia }\end{array}$} & $10 / 05 / 2007$ & $31 / 01 / 2005$ \\
\hline & & 11/07/2008 & $22 / 05 / 2008$ \\
\hline Chaitén & Chile & 02/05/2008 & $11 / 12 / 2009$ \\
\hline \multirow[t]{2}{*}{ Dukono } & \multirow[t]{2}{*}{ Indonesia } & $25 / 05 / 2008$ & 03/03/2006 \\
\hline & & 25/07/2008 & 02/10/2008 \\
\hline Fuego & Guatemala & $27 / 12 / 2005$ & 03/04/2008 \\
\hline Ibu & Indonesia & $04 / 04 / 2008$ & $16 / 07 / 2008$ \\
\hline \multirow[t]{4}{*}{ Kathala } & \multirow[t]{4}{*}{ Comoros } & $16 / 04 / 2005$ & 07/07/2005 \\
\hline & & $24 / 11 / 2005$ & $12 / 09 / 2006$ \\
\hline & & $28 / 05 / 2006$ & $17 / 10 / 2008$ \\
\hline & & $12 / 01 / 2007$ & 24/05/2009 \\
\hline Kelut & Indonesia & $18 / 05 / 2006$ & $21 / 02 / 2006$ \\
\hline \multirow[t]{5}{*}{ Manam } & Papua & $27 / 01 / 2005$ & $15 / 07 / 2005$ \\
\hline & \multirow[t]{4}{*}{ New Guinea } & $17 / 07 / 2006$ & $25 / 02 / 2005$ \\
\hline & & 05/10/2007 & $24 / 11 / 2008$ \\
\hline & & $29 / 12 / 2007$ & 07/08/2005 \\
\hline & & $11 / 05 / 2008$ & 04/07/2008 \\
\hline \multirow[t]{2}{*}{ Mayon } & \multirow[t]{2}{*}{ Philippines } & $17 / 08 / 2005$ & 02/08/2006 \\
\hline & & $21 / 02 / 2006$ & 27/03/2008 \\
\hline \multirow[t]{2}{*}{ Merapi } & \multirow[t]{2}{*}{ Indonesia } & 07/03/2006 & 29/05/2008 \\
\hline & & $11 / 03 / 2006$ & $31 / 03 / 2007$ \\
\hline \multirow[t]{4}{*}{ Nyamuragira } & \multirow[t]{4}{*}{ DR Congo } & $27 / 11 / 2006$ & 09/12/2007 \\
\hline & & $02 / 01 / 2010$ & $11 / 05 / 2009$ \\
\hline & & $06 / 11 / 2011$ & 03/09/2008 \\
\hline & & $22 / 06 / 2014$ & $31 / 08 / 2008$ \\
\hline \multirow[t]{4}{*}{ Nyiragongo } & \multirow[t]{4}{*}{ DR Congo } & 07/09/2005 & $22 / 06 / 2006$ \\
\hline & & $10 / 10 / 2005$ & 27/08/2005 \\
\hline & & $07 / 11 / 2005$ & 08/03/2007 \\
\hline & & 01/01/2009 & 09/05/2009 \\
\hline
\end{tabular}


Table 2. Continued.

\begin{tabular}{|c|c|c|c|}
\hline Volcano & Location & Eruption date & Control date \\
\hline Ol Doinyo & \multirow[t]{2}{*}{ Tanzania } & $20 / 07 / 2005$ & $20 / 07 / 2005$ \\
\hline Lengai & & $30 / 03 / 2006$ & $11 / 03 / 2008$ \\
\hline \multirow[t]{2}{*}{ Pagan } & Mariana & $11 / 01 / 2007$ & $24 / 06 / 2007$ \\
\hline & Islands & & \\
\hline \multirow{3}{*}{$\begin{array}{l}\text { Piton de la } \\
\text { Fournaise }\end{array}$} & \multirow[t]{3}{*}{ Réunion } & $24 / 02 / 2005$ & $01 / 02 / 2006$ \\
\hline & & 20/07/2006 & $22 / 03 / 2007$ \\
\hline & & $30 / 08 / 2006$ & $13 / 11 / 2008$ \\
\hline \multirow[t]{6}{*}{ Popocatépetl } & \multirow[t]{6}{*}{ Mexico } & $06 / 04 / 2006$ & $22 / 02 / 2006$ \\
\hline & & $23 / 05 / 2006$ & $27 / 08 / 2005$ \\
\hline & & $11 / 04 / 2007$ & 08/03/2007 \\
\hline & & $01 / 12 / 2007$ & 09/05/2009 \\
\hline & & $22 / 02 / 2008$ & $25 / 02 / 2005$ \\
\hline & & $16 / 11 / 2008$ & $11 / 03 / 2008$ \\
\hline \multirow[t]{3}{*}{ Rabaul } & Papua & $07 / 10 / 2006$ & $24 / 06 / 2007$ \\
\hline & \multirow{2}{*}{ New Guinea } & 04/08/2007 & $01 / 02 / 2006$ \\
\hline & & $22 / 08 / 2007$ & $22 / 03 / 2007$ \\
\hline Santa Ana & El Salvador & 01/10/2005 & $13 / 11 / 2008$ \\
\hline Santa Maria & Guatemala & $26 / 10 / 2005$ & $22 / 02 / 2006$ \\
\hline \multirow[t]{4}{*}{ SHV } & \multirow[t]{4}{*}{ Montserrat } & $20 / 05 / 2006$ & $10 / 04 / 2009$ \\
\hline & & 08/01/2007 & $12 / 03 / 2008$ \\
\hline & & 29/07/2008 & 05/06/2007 \\
\hline & & $11 / 02 / 2010$ & $02 / 04 / 2007$ \\
\hline \multirow[t]{4}{*}{ Soputan } & \multirow[t]{4}{*}{ Indonesia } & $19 / 04 / 2005$ & $07 / 02 / 2005$ \\
\hline & & $15 / 12 / 2006$ & $10 / 05 / 2009$ \\
\hline & & $15 / 12 / 2006$ & $17 / 11 / 2008$ \\
\hline & & 06/06/2008 & $20 / 12 / 2006$ \\
\hline \multirow[t]{3}{*}{ Tinakula } & \multirow{3}{*}{$\begin{array}{l}\text { Solomon } \\
\text { Islands }\end{array}$} & $12 / 02 / 2006$ & 03/02/2009 \\
\hline & & 22/09/2009 & $15 / 06 / 2009$ \\
\hline & & $17 / 01 / 2010$ & $05 / 10 / 2005$ \\
\hline \multirow[t]{4}{*}{ Tungurahua } & \multirow[t]{4}{*}{ Ecuador } & $14 / 07 / 2006$ & $16 / 06 / 2005$ \\
\hline & & $16 / 08 / 2006$ & $31 / 12 / 2009$ \\
\hline & & $10 / 01 / 2008$ & $04 / 05 / 2009$ \\
\hline & & $06 / 02 / 2008$ & $11 / 02 / 2007$ \\
\hline \multirow[t]{2}{*}{ Turrialba } & \multirow[t]{2}{*}{ Costa Rica } & 06/01/2010 & $06 / 09 / 2005$ \\
\hline & & $12 / 01 / 2012$ & $04 / 08 / 2005$ \\
\hline
\end{tabular}

Dates are displayed as DD/MM/YYY.

latitudes. Cloud masking is due to the high UV albedo of clouds, and this, coupled with low UV irradiance, can make $\mathrm{SO}_{2}$ detection at high latitudes during winter months particularly challenging (Telling et al., 2015). Through implementation of a cloud fraction threshold of $\sim 20 \%$ within each scene the majority of the eruptions analysed here were restricted to latitudes below $30^{\circ}$.

\subsection{Control samples}

A control group is required to assess whether volcanic eruptions can be distinguished from background $\mathrm{SO}_{2}$ levels. Therefore, for each volcanic eruption analysed (Table 2) a control $\mathrm{SO}_{2}$ mass was calculated using each of the three incorporated methodologies $\left(\mathrm{M}_{1}, \mathrm{M}_{2}\right.$, and $\left.\mathrm{M}_{3}\right)$ for a second date at the same volcano. Assignment of control group analysis dates was limited to a period between 1 January 2005 and 31 December 2009. The 2009 cut-off date was employed due to the increasing influence of the ORA after this time, in an attempt to reduce the influence of data gaps on the model output. Control dates were assigned for comparison with each identified volcanic eruption, using an online random-number generator (Haahr, 2015; http://www.random.org) to assign a value between 0 and 1825 to each data point. These random values were used to determine the number days from the beginning of the analysis period at which to assign a control date (Table 2). The identified dates were then assigned to each target volcano alphabetically, with a corresponding number of events assigned to each location as number of volcanic eruption analyses performed (Table 2).

\subsection{Modelling techniques}

Modelling procedures were conducted with the Weka 3 software package: a collection of algorithms that can be implemented for data mining tasks (Hall et al., 2009) provided by the University of Waikato (http://www.cs.waikato.ac.nz/ml/ weka/). The quantity of $\mathrm{SO}_{2}$ present within each analysis region is a complex function of eruption composition and magnitude in addition to ambient $\mathrm{SO}_{2}$ levels and local sources of interference such as neighbouring volcanoes. This precludes the use of a fixed threshold, whereas statistical models permit a probabilistic approach to volcanic eruption identification with multiple statistical analyses trialled using the Weka 3 package. A simple logistic regression analysis (Eq. 2) was found to be the most effective technique for the classification of volcanic and non-volcanic events. Simple logistic regression is a binary classification technique, here defining volcanic $(v)$ and non-volcanic control $(c)$ events and facilitating the development of a linear model constructed from a transformed target variable (Witten and Frank, 2005). The logistic regression equation used here assigns the probability $P$ of the occurrence of a volcanic eruption or degassing event:

$P=1-\frac{1}{1+e^{-(a+b X)}}$,

where $e$ is the base of the natural logarithm, $a$ is the probability when the independent variable $(X$; here, the volcanic plume $\mathrm{SO}_{2}$ mass measured is in tonnes) is equal to 0 , and $b$ represents the rate at which probabilities vary with incremental changes in $X$.

Output of a logistic regression analysis is assessed against a series of validation statistics that test the accuracy of the 
generated model. These statistics include overall accuracy, precision, and recall, in addition to receiver operating characteristic (ROC) curves. In this analysis, the overall accuracy relates to the percentage of correctly classified events in both the volcanic and control (non-volcanic) samples; however, this statistic alone cannot account for preferential classification of one sample over another (Oommen et al., 2010). Hence precision and recall statistics, characterised by values between 0 and 1 , are used to identify whether preferential classification is occurring. Precision relates to the accuracy of prediction of a single sample group (volcanic or non-volcanic), whilst recall measures the effectiveness of the predictions themselves (Oommen et al., 2010). In the context of this study, if a volcanic classification has a precision of 0.9 , then $90 \%$ of the events predicted as being volcanic in nature are volcanic events, whilst the remaining $10 \%$ are misclassified as non-volcanic and will be termed here as "missed alerts". In contrast, a recall value of 0.8 would correspond to $80 \%$ of observed volcanic events being correctly classified, but this does not take into account any non-volcanic events which are misclassified as volcanic, referred to here as "false alerts". The final validation statistic used here is the ROC curve, which represents a method for assessing the rate of accurately classified events against possible falsely classified events. ROC values relate to the accuracy of the classification system implemented, with a value of 1 indicating accurate prediction of all events (Oommen et al., 2010; Witten and Frank, 2005).

Logistic regression model calculation was conducted using the $k$-fold cross-validation technique incorporated into the Weka 3 software package. This method segregates the data into $k$ partitions, allowing $k-1$ segments of the data to be used as a training set, with the remaining data used for validation purposes. This method is then repeated with each of the $k$ partitions being used to validate the corresponding model from which it was withheld, with the final statistics comprising an average of the output of all $k$ models (Oommen et al., 2010). We implement a $k$ value of 10 due to the associated reduction in bias compared to $k$ values $<5$ (Rodríguez et al., 2010; Witten and Frank, 2005).

\section{Results}

Of the three $\mathrm{SO}_{2}$ mass calculation procedures employed $\left(\mathrm{M}_{1}, \mathrm{M}_{2}\right.$, and $\left.\mathrm{M}_{3}\right)$, the most success was achieved with the background-corrected dataset $\left(\mathrm{M}_{3}\right)$. None of the logistic regression model investigations undertaken with the $M_{1}$ and $\mathrm{M}_{2}$ datasets produced more than $55 \%$ overall accuracy in the classification of volcanic events, and therefore these data were not investigated further. In contrast, the $\mathrm{M}_{3}$ technique provided the best results, with a $77 \%$ overall accuracy and no additional data pre-processing required; therefore this technique was employed for all further assessments and model development.
Table 3. Average $\mathrm{SO}_{2}$ column amounts (tonnes) for volcanic and control events.

\begin{tabular}{llr}
\hline Sample & & $\begin{array}{r}\text { Average } \mathrm{SO}_{2} \\
\text { mass (tonnes) }\end{array}$ \\
\hline Volcanic & $\mathrm{M}_{1}\left(4^{\circ}\right)$ & 2680 \\
& $\mathrm{M}_{2}\left(2^{\circ}\right)$ & 1150 \\
& $\mathrm{M}_{3}$ (corrected) & 680 \\
\hline Control & $\mathrm{M}_{1}\left(4^{\circ}\right)$ & 450 \\
& $\mathrm{M}_{2}\left(2^{\circ}\right)$ & 170 \\
& $\mathrm{M}_{3}$ (corrected) & 90 \\
\hline
\end{tabular}

\section{1 $\mathrm{OMI} \mathrm{SO}_{2}$ measurements}

Of the 79 volcanic eruptions analysed, 13 displayed low $\mathrm{SO}_{2}$ amounts $\left(<100 \mathrm{t}\right.$ ), following application of the $\mathrm{SO}_{2}$ correction $\left(\mathrm{M}_{3}\right)$, on the identified day of eruption. Two eruptions produced very large amounts of $\mathrm{SO}_{2}$ : Nyamuragira (November 2006; 46 kt) and Rabaul (October 2006; $550 \mathrm{kt}$ ); however, use of the OMI TRL $\mathrm{SO}_{2}$ columns is likely to overestimate the actual $\mathrm{SO}_{2}$ amounts in these upper-tropospheric or lowerstratospheric plumes (Carn et al., 2013).

Excluding the aforementioned very high values, the average $\mathrm{M}_{3}$ plume contained $680 \mathrm{t}$ of $\mathrm{SO}_{2}$, approximately $60 \%$ of the average of the $\mathrm{M}_{2}$ analysis and $25 \%$ of the $\mathrm{M}_{1}$ average (Table 3). The control dataset displays significantly lower $\mathrm{SO}_{2}$ loadings than the volcanic events, with an average corrected $\mathrm{SO}_{2}$ mass of $90 \mathrm{t}$ and a maximum corrected $\mathrm{SO}_{2}$ mass of $1040 \mathrm{t}$. This variation indicates that the volcanic data displays generally higher $\mathrm{SO}_{2}$ levels than the control data, as would be expected. In all of the selection methodologies the $\mathrm{SO}_{2}$ mass detected on control dates was $14-17 \%$ of the average mass detected in the volcanic dataset. Box plots were generated to assess the general dynamics of the volcanic and control datasets (Fig. 2). Comparison of these plots confirms the pattern identified in Table 3, with the $\mathrm{SO}_{2}$ measurements on "eruption" days displaying significantly higher values than the control data.

\subsection{Model output}

The most accurate model consisted of a simple logistic regression applied to the $\mathrm{M}_{3} \mathrm{SO}_{2}$ dataset with an overall accuracy of $76.6 \%$ and an ROC of 0.843 . This model favoured volcanic precision (volcanic precision of 0.83 vs. control precision of 0.72) at the expense of control recall (control recall of 0.86 vs. volcanic recall of 0.67 ), which indicates that the model preferentially classifies alerts as control samples. This model reduces the number of false alerts generated relative to missed alerts. Investigations were undertaken to identify characteristics of volcanic events that facilitated classification and to elucidate the likely cause of the $23 \%$ error associated with the model. Removal of volcanic plumes containing less than $50 \mathrm{t}$ of $\mathrm{SO}_{2}$ from the $\mathrm{M}_{3}$ dataset resulted in 


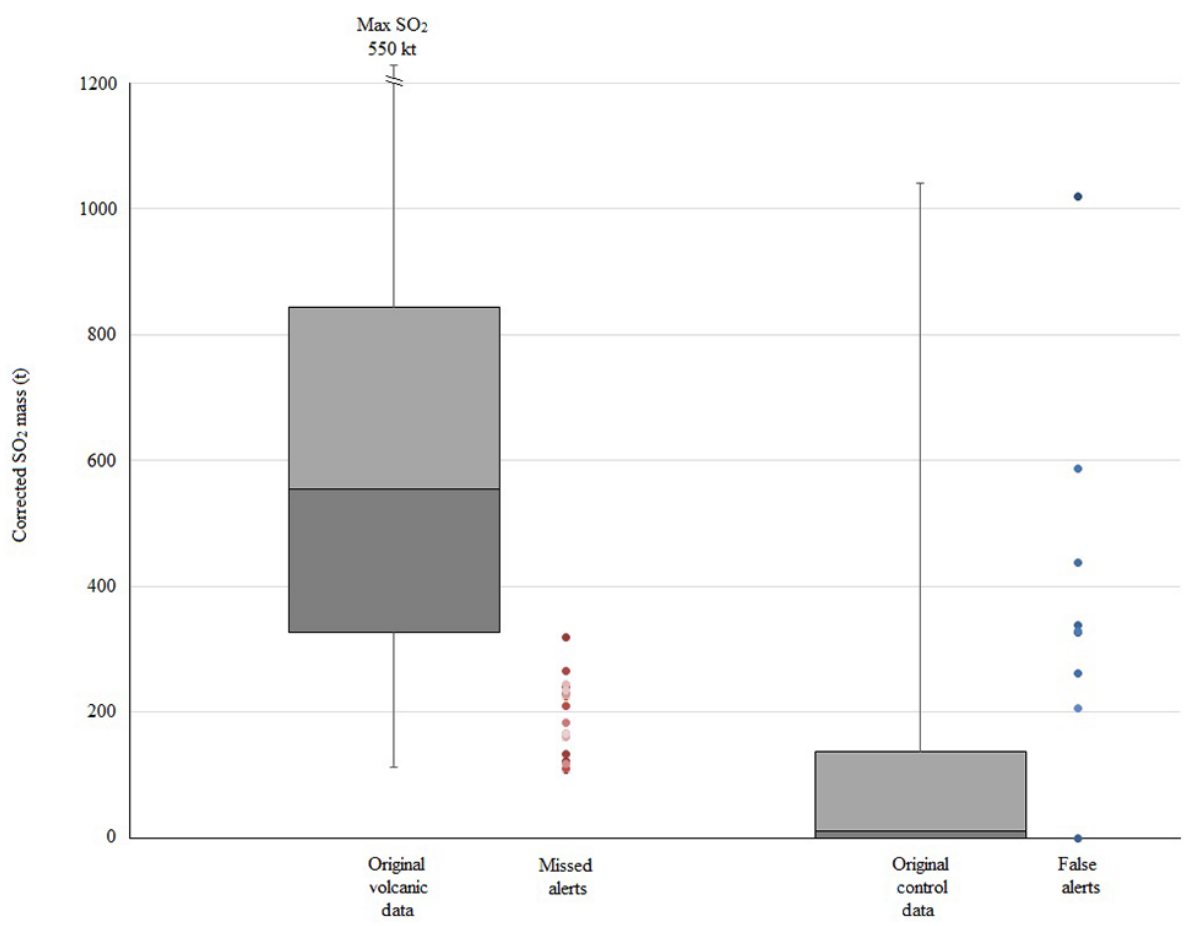

Figure 2. Box-and-whisker plots displaying the spread and distribution of volcanic and control data, with lines indicating upper and lower quartiles of the data and the remainder represented by the box region. Additional data points indicate the individual missed alerts in the volcanic data and false alerts in the control data detailed in Table 4.

a $\sim 6 \%$ increase in model accuracy. Eight data points produced false alerts with control events classified as volcanic eruptions, whilst 18 volcanic events were misclassified as controls, producing missed alerts (Table 4). The misclassified alerts were isolated to assess if any common characteristics of these events could be identified, with each individual alert incorporated into Fig. 2 for comparison with the overall dynamics of the data. The comparison of missed alerts indicates that each one falls within the lower quartile of the volcanic dataset, whilst the false alerts displayed values consistent with the upper quartile of the control data range (with one exception; see Fig. 2). The potential causes of the misclassification of events are discussed further in Sect. 4.1.

\section{Discussion}

\subsection{Analysis of inaccurate classifications}

\subsubsection{False alerts}

Investigation of the incorrectly classified false alerts (Fig. 2; Table 4) revealed that, due to the random selection procedure used for assigning control sample dates, some of the control $\mathrm{SO}_{2}$ values corresponded to periods of ongoing volcanic activity. These anomalous control values relate to stronger, persistent plumes, despite not being associated with large or "initiating" events as reported in the VOTW database; this was the case for five of the nine false alerts $(\mathrm{C} 1,8,32,54$, and
57; Table 4). Two additional alerts were generated as a result of a data gap in the OMI measurements (C10 and 24). Missing values (characterised by a blank cell to differentiate these from days with data available but no recordable $\mathrm{SO}_{2}$ emissions) are incorrectly classified by the incorporated model as volcanic events. Pre-screening of samples for data gaps prior to incorporation into the model is required to prevent the classification of missing values as volcanic events. The one remaining false alert (C29) was the result of increased noise levels preferentially affecting the $\mathrm{M}_{2}$ over the $\mathrm{M}_{1}$ region, resulting in an artificially high $\mathrm{SO}_{2}$ mass derived from the $\mathrm{M}_{3}$ calculation and a false alert.

\subsubsection{Missed alerts}

Missed alerts occurred at a higher frequency than false alerts, but a common characteristic of all missed alerts is an $\mathrm{SO}_{2}$ plume mass below $325 \mathrm{t}$ (Fig. 2; Table 4). We attribute the misclassification of volcanic events to four main causes. The first influenced eight of the volcanic events (V3, 13, 20, 23, $28,32,33$, and 48; Table 4) and is the result of eruptions producing diffuse plumes containing low $\mathrm{SO}_{2}$ amounts close to the OMI detection limit (e.g. small eruptions and/or eruptions to low altitudes). The second cause of misclassification affecting eight samples (V5, 17, 21, 24, 34, 43, 64, and 67; Table 4) is the drifting of the volcanic plume out of the geographic area of analysis $\left(\mathrm{M}_{2}\right)$ into the region utilised for background classification $\left(\mathrm{M}_{1}\right)$, causing signal suppres- 
Table 4. Misclassified alerts identified in the initial logistic regression model.

\begin{tabular}{|c|c|c|c|c|c|c|c|}
\hline \multicolumn{2}{|c|}{$\begin{array}{c}\text { Sample } \\
\text { (S) }\end{array}$} & \multirow{2}{*}{$\begin{array}{l}\text { Name } \\
\text { Ambrym }\end{array}$} & \multirow{2}{*}{$\begin{array}{l}\begin{array}{l}\text { Date } \\
(\mathrm{DD} / \mathrm{MM} / \mathrm{YYYY})\end{array} \\
31 / 03 / 2005\end{array}$} & \multirow{2}{*}{$\begin{array}{r}\begin{array}{r}\text { Plume } \mathrm{SO}_{2} \\
\text { mass (tonnes) }\end{array} \\
1040\end{array}$} & \multirow{2}{*}{$\begin{array}{l}\begin{array}{l}\text { Predicted } \\
\text { classification }\end{array} \\
\text { Volcanic }\end{array}$} & \multirow{2}{*}{$\begin{array}{l}\text { Original } \\
\text { classification }\end{array}$} & \multirow{2}{*}{$\begin{array}{l}\text { Error generation } \\
\text { Persistent degassing }\end{array}$} \\
\hline $\mathrm{C}$ & 1 & & & & & & \\
\hline $\mathrm{C}$ & 8 & Bagana & $26 / 11 / 2007$ & 340 & Volcanic & Control & Persistent degassing \\
\hline $\mathrm{C}$ & 10 & Bagana & $23 / 10 / 2006$ & $?$ & Volcanic & Control & Missing data \\
\hline $\mathrm{C}$ & 24 & Karthala & 07/07/2005 & $?$ & Volcanic & Control & Missing data \\
\hline $\mathrm{C}$ & 29 & Manam & $15 / 07 / 2005$ & 350 & Volcanic & Control & Localised noise \\
\hline $\mathrm{C}$ & 32 & Manam & 07/08/2005 & 450 & Volcanic & Control & Small Eruption \\
\hline $\mathrm{C}$ & 54 & Popocatépetl & 08/03/2007 & 600 & Volcanic & Control & Ongoing eruption \\
\hline $\mathrm{C}$ & 57 & Popocatépetl & $11 / 03 / 2008$ & 340 & Volcanic & Control & Ongoing eruption \\
\hline V & 3 & Anatahan & 06/01/2005 & 230 & Control & Volcanic & Diffuse plume \\
\hline V & 5 & Anatahan & $17 / 03 / 2006$ & 120 & Control & Volcanic & Drifting plume \\
\hline $\mathrm{V}$ & 13 & Bagana & $14 / 07 / 2007$ & 320 & Control & Volcanic & Diffuse plume \\
\hline V & 17 & Bezymianny & $10 / 05 / 2007$ & 140 & Control & Volcanic & Drifting plume \\
\hline $\mathrm{V}$ & 19 & Chaiten & 02/05/2008 & 250 & Control & Volcanic & High noise \\
\hline $\mathrm{V}$ & 20 & Dukono & $25 / 05 / 2008$ & 300 & Control & Volcanic & Diffuse plume \\
\hline V & 21 & Dukono & $25 / 07 / 2008$ & 270 & Control & Volcanic & Drifting plume \\
\hline V & 23 & Ibu & 04/04/2008 & 210 & Control & Volcanic & Diffuse plume \\
\hline V & 24 & Karthala & $16 / 04 / 2005$ & 110 & Control & Volcanic & Drifting plume \\
\hline V & 28 & Kelut & $18 / 05 / 2006$ & 170 & Control & Volcanic & Diffuse plume \\
\hline V & 32 & Manam & $29 / 12 / 2007$ & 80 & Control & Volcanic & Diffuse plume \\
\hline V & 33 & Manam & $11 / 05 / 2008$ & 190 & Control & Volcanic & Diffuse plume \\
\hline V & 34 & Mayon & $17 / 08 / 2005$ & 120 & Control & Volcanic & Drifting plume \\
\hline $\mathrm{V}$ & 43 & Nyiragongo & $10 / 10 / 2005$ & 230 & Control & Volcanic & Drifting plume \\
\hline $\mathrm{V}$ & 48 & Pagan & $11 / 01 / 2007$ & 160 & Control & Volcanic & Diffuse plume \\
\hline V & 53 & Popocatépetl & $23 / 05 / 2006$ & 250 & Control & Volcanic & Interfering signal \\
\hline V & 64 & SHV & 08/01/2007 & 240 & Control & Volcanic & Drifting plume \\
\hline $\mathrm{V}$ & 67 & Soputan & $19 / 04 / 2005$ & 170 & Control & Volcanic & Drifting plume \\
\hline
\end{tabular}

sion in the $\mathrm{M}_{3}$ methodology. Implementation of this system on a global grid would allow the identification of drifting plumes in addition to those located directly above the corresponding emitting source. One event (V19; Table 4) was impacted by increased noise in the background classification region, also suppressing the plume $\mathrm{SO}_{2}$ loading in the $\mathrm{M}_{3}$ calculation. The final factor preventing the correct identification of a volcanic eruption (V53; Table 4) occurred at Popocatépetl (Mexico), through the masking of a moderate eruption plume when a large $\mathrm{SO}_{2}$ cloud from another volcano (Soufrière Hills, Montserrat) drifted into the $\mathrm{M}_{1}$ region, causing an anomalously high background $\mathrm{SO}_{2}$ mass in the $\mathrm{M}_{3}$ calculation.

\subsection{Optimisation of event classification}

We assessed the impact of varying the maximum $\mathrm{SO}_{2}$ plume mass included in the logistic regression model to investigate whether the use of a threshold $\mathrm{SO}_{2}$ loading improved the classification capabilities of the model. The volcanic dataset was incrementally filtered to remove a proportion of the data, to identify how this influenced the validation statistics. Each reduced volcanic dataset was incorporated into a logistical regression model with a $k$-fold validation system; however, the control sample was maintained throughout all of the analyses. The variation in class size produced by the removal of volcanic data actually provides a more accurate representation of the natural system (Oommen et al., 2011), with more control samples than volcanic, as more days are characterised by quiescence than volcanic activity. In each instance the overall accuracy, precision, and recall statistics were tracked (Fig. 3) to assess the changes in the model as the minimum incorporated $\mathrm{SO}_{2}$ mass varied. The linear correlation between control recall and volcanic precision is evident in the comparison of these statistics (Fig. 3b) as well as that between the control precision and volcanic recall.

When all data are incorporated, the model appears to favour volcanic precision and control recall, resulting in a model that will display a larger number of missed volcanic alerts than false classification of control samples. When $60 \%$ of the dataset is used, the volcanic precision and recall are equal, as are the control precision and recall, all displaying values greater than 0.9 . The threshold $\mathrm{SO}_{2}$ loading in this case is $360 \mathrm{t}$; i.e. if this model were to be implemented, any volcanic plume containing less than this amount would not be identified as a volcanic event. The use of $75 \%$ of the volcanic dataset appears to represent a good compromise between variation in the statistics and the elimination of smaller 

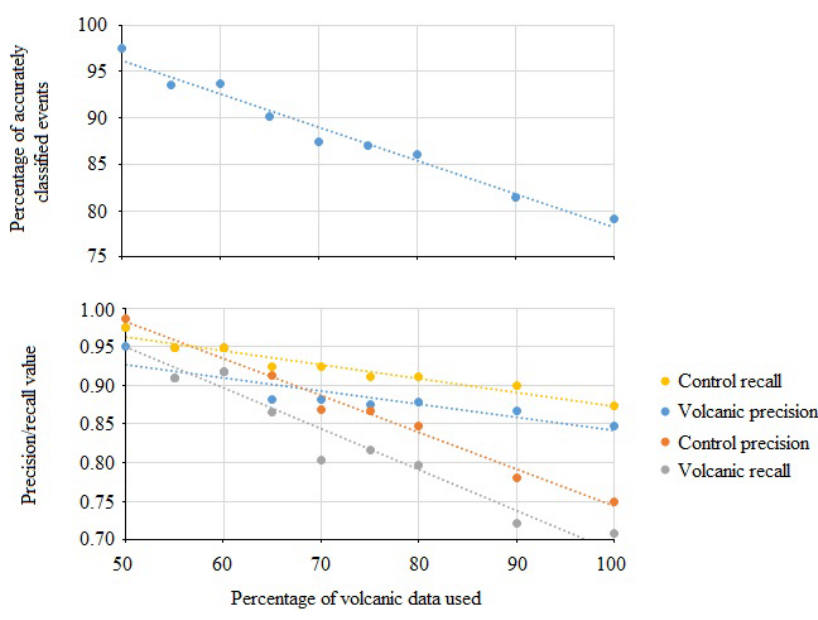

Figure 3. Result of the application of a threshold $\mathrm{SO}_{2}$ loading to the volcanic dataset on (a) accurately classified events and (b) the precision (no false alerts) and recall (no missed alerts) values for both the volcanic and control datasets.

plumes (Fig. 3). The volcanic and control precision are almost equal, indicating that this model is equally effective at predicting volcanic and non-volcanic events, with a higher control recall than volcanic recall (Fig. 3). The tendency of this model is to miss smaller volcanic events rather than falsely classify control samples displaying moderate noise levels. Favouring missed over false alerts is also a characteristic of the MODVOLC MODIS-based automatic volcanic alert system (http://modis.higp.hawaii.edu/), designed to detect volcanic thermal anomalies. Quantitative comparison of these models could not be conducted as assessment of the MODVOLC system was performed in a more qualitative manner, assessing whether alerts were identified in locations where they would be expected (e.g. lava flow fields) (Wright et al., 2002, 2004).

Figure 4 shows the variation of ROC values associated with each of the logistic regression models and minimum $\mathrm{SO}_{2}$ plume mass with the percentage of the total dataset analysed, with the total change in each normalised. The trends in both ROC and $\mathrm{SO}_{2}$ mass threshold show second-order polynomial characteristics with $R^{2}$ values of 0.985 and 0.993 respectively. The intersection of these trend lines represents model optimisation, offering the greatest gain in accuracy (ROC) combined with the least impact on the identifiable $\mathrm{SO}_{2}$ plume mass. This optimisation point corresponds to the removal of $22 \%$ of the volcanic data, resulting in a minimum incorporated $\mathrm{SO}_{2}$ mass of $\sim 150 \mathrm{t}$, and correlates with that inferred through the comparison of precision and recall statistics (Fig. 3). Application of a $150 \mathrm{t} \mathrm{SO}_{2}$ mass threshold prevents the resolution of smaller plumes, but the original assessment (Fig. 2; Table 4) indicates that $\mathrm{SO}_{2}$ loadings below this value tended to be misclassified anyway.

The model based on $78 \%$ of the volcanic dataset has an overall accuracy of $85.7 \%$ and an ROC of 0.95 , produc-

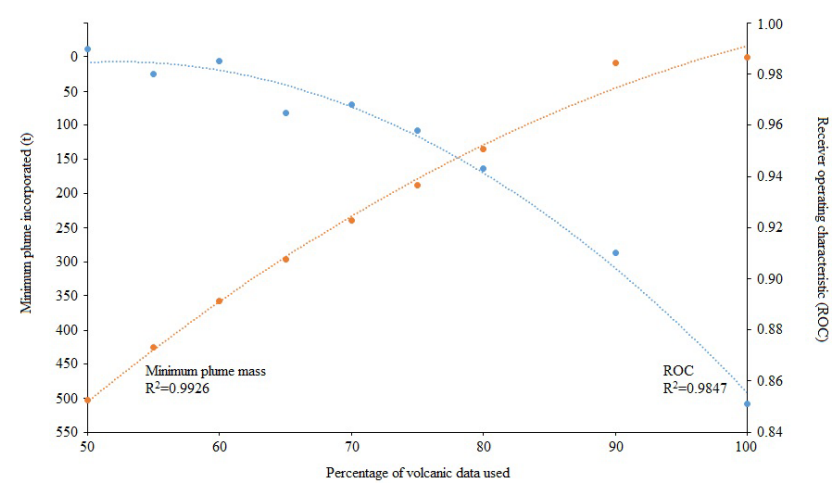

Figure 4. The effect of proportional removal of lowest data points on minimum incorporated $\mathrm{SO}_{2}$ mass from the volcanic dataset and the ROC (receiver operator characteristic) statistic of each model where $\mathrm{ROC}=1$ implies all events correctly classified.

ing eight false alerts that correspond to those identified in the original assessment, with the exception of C8 (Table 4), which was accurately classified with this model. In contrast, $27.8 \%$ of the missed alerts originally identified were no longer flagged; of these five instances, four were eliminated due to their low $\mathrm{SO}_{2}$ loadings, with the remaining alert correctly classified as a result of improvements in event classification by the optimised model.

Parameterisation of Eq. (2) using the $78 \%$ model output facilitates the validation of individual records and allows the incorporation of new data points (Eq. 3) through the substitution of $X$ with measured volcanic $\mathrm{SO}_{2}$ mass in tonnes:

$$
P=1-\frac{1}{1+e^{-(-2.943+0.0091 X)}} .
$$

\subsection{Independent validation}

A secondary testing procedure was employed to assess the efficacy of the developed logistic regression models on an independent test dataset consisting of 12 volcanic eruptions not initially included (Global Volcanism Program, 2013) and displaying variable plume characteristics, and 12 corresponding control samples, resulting in 24 data points (Table 5).

The incorporation of an independent investigation allowed the data characteristics isolated in the original analysis to be tested against data not utilised in the training of the model. Classification of the data with the original model containing all data points resulted in an accuracy of $75 \%$, whereas analysis with the optimised model ( $78 \%$ of the data) produced an overall accuracy of $79.2 \%$; a detailed overview of the validation statistics of each model is given in Table 6 . The optimised model resulted in no false detections although four volcanic events were missed; these consisted of one sample in which the $\mathrm{SO}_{2}$ plume had drifted out of the analysis area (Soufrière Hills), two weak plumes with $\mathrm{SO}_{2}$ loadings below $60 \mathrm{t}$ (Cleveland \& Lascar), and one moderate plume with $\mathrm{SO}_{2}$ loadings of $255 \mathrm{t}$ (Colima). All $\mathrm{SO}_{2}$ plumes exceeding 
Table 5. Locations and dates of volcanic and control "eruptions" for validation dataset.

\begin{tabular}{|c|c|c|c|c|c|c|c|}
\hline \multirow[t]{2}{*}{ Volcano } & \multirow[t]{2}{*}{ Location } & \multirow{2}{*}{$\begin{array}{l}\text { Eruption } \\
\text { date } \\
\text { (DD/MM/YYY) }\end{array}$} & \multicolumn{2}{|c|}{$\begin{array}{l}\text { Correct classification } \\
\qquad(\mathrm{Y} / \mathrm{N})\end{array}$} & \multirow{2}{*}{$\begin{array}{l}\text { Control } \\
\text { date } \\
(\mathrm{DD} / \mathrm{MM} / \mathrm{YYY})\end{array}$} & \multicolumn{2}{|c|}{$\begin{array}{c}\text { Correct classification } \\
(\mathrm{Y} / \mathrm{N})\end{array}$} \\
\hline & & & Original & Optimised & & Original & Optimised \\
\hline Ambrym & Vanuatu & 01/05/2007 & $\mathrm{N}$ & $\mathrm{Y}$ & $12 / 12 / 2008$ & $\mathrm{~N}$ & $\mathrm{Y}$ \\
\hline Anatahan & Mariana Islands & $29 / 05 / 2006$ & $\mathrm{Y}$ & $\mathrm{Y}$ & 06/09/2005 & $\mathrm{Y}$ & $\mathrm{Y}$ \\
\hline \multirow[t]{3}{*}{ Cleveland } & Aleutian & 06/02/2006 & $\mathrm{Y}$ & $\mathrm{Y}$ & $17 / 05 / 2009$ & $\mathrm{Y}$ & $\mathrm{Y}$ \\
\hline & Islands & $23 / 05 / 2006$ & $\mathrm{Y}$ & $\mathrm{Y}$ & 06/01/2008 & $\mathrm{Y}$ & $\mathrm{Y}$ \\
\hline & & $28 / 10 / 2006$ & $\mathrm{~N}$ & $\mathrm{~N}$ & $28 / 02 / 2006$ & $\mathrm{~N}$ & $\mathrm{~N}$ \\
\hline Colima & Mexico & $24 / 04 / 2005$ & $\mathrm{~N}$ & $\mathrm{~N}$ & 04/05/2009 & $\mathrm{Y}$ & $\mathrm{Y}$ \\
\hline Lascar & Chile & $04 / 05 / 2005$ & $\mathrm{~N}$ & $\mathrm{~N}$ & $11 / 02 / 2007$ & $\mathrm{Y}$ & $\mathrm{Y}$ \\
\hline Lopevi & Vanuatu & $21 / 04 / 2007$ & $\mathrm{Y}$ & $\mathrm{Y}$ & $13 / 12 / 2006$ & $\mathrm{Y}$ & $\mathrm{Y}$ \\
\hline Okmok & Aleutian Islands & $12 / 07 / 2008$ & $\mathrm{Y}$ & $\mathrm{Y}$ & 01/07/2008 & $\mathrm{Y}$ & $\mathrm{Y}$ \\
\hline Sierra Negra & Galápagos Islands & $22 / 10 / 2005$ & $\mathrm{Y}$ & $\mathrm{Y}$ & $04 / 08 / 2005$ & $\mathrm{Y}$ & $\mathrm{Y}$ \\
\hline Soputan & Indonesia & $25 / 10 / 2007$ & $\mathrm{Y}$ & $\mathrm{Y}$ & 02/07/2008 & $\mathrm{Y}$ & $\mathrm{Y}$ \\
\hline Soufrière Hills & Montserrat & $20 / 05 / 2006$ & $\mathrm{~N}$ & $\mathrm{~N}$ & $24 / 08 / 2006$ & $\mathrm{Y}$ & $\mathrm{Y}$ \\
\hline
\end{tabular}

Table 6. Validation statistics generated through the assessment of the test data with three methods.

\begin{tabular}{lrrr}
\hline Validation statistic & $\begin{array}{r}\text { Original } \\
\text { model }\end{array}$ & $\begin{array}{r}\text { Optimised } \\
\text { model }\end{array}$ & $\begin{array}{r}\text { Optimised } \\
\text { threshold model }\end{array}$ \\
\hline Overall accuracy (\%) & 75 & 79.2 & 95 \\
Volcanic precision & 0.8 & 1 & 1 \\
Volcanic recall & 0.667 & 0.583 & 0.889 \\
Control precision & 0.714 & 0.706 & 0.917 \\
Control recall & 0.833 & 1 & 1 \\
ROC & 0.813 & 0.84 & 0.979 \\
Threshold $(P)$ & 0.432 & 0.620 & 0.660 \\
\hline
\end{tabular}

$390 \mathrm{t}$ were correctly classified as volcanic; therefore we conclude that events emitting less than $390 \mathrm{t} \mathrm{SO}_{2}$ are likely to be misclassified with this methodology. Taking into account the thresholds of the incorporated methods (Table 6) and solving Eq. (3), we find that the minimum $\mathrm{SO}_{2}$ mass that would be classified as volcanic in origin by this model is $378 \mathrm{t}$.

\subsection{Limitations}

This analysis has indicated that, prior to implementation of the incorporated classification technique (logistic regression), pre-screening of data samples is required to account for the influence of missing data points and meteorological cloud cover. The incorporated modelling technique automatically interpreted missing values as volcanic alerts, thus influencing the calculated threshold, and therefore data gaps must be removed prior to logistic regression analysis. Persistent meteorological cloud cover can mask $\mathrm{SO}_{2}$ plumes at lower altitudes from satellite sensors, precluding detection. This effect can be significant at higher latitudes, particularly in winter, and therefore the methodology described here may be limited at these locations. Where high-latitude data were available and incorporated into this trial (Bezymianny,
Okmok, and Cleveland), correct classification occurred on all but one of those days for which data were available (one additional control sample characterised by no available data was misclassified). Consistent high-latitude classification indicates the robust nature of the $\mathrm{M}_{3}$ pre-processing technique employed, with no indication that differences in sample region size due to latitudinal variations (discussed in Sect. 2.2) influenced the identification of volcanic clouds. Further investigation is necessary to accurately assess the capabilities of the technique in high-latitude regions, particularly regarding the influence of persistent cloud cover.

The main constraint on $\mathrm{SO}_{2}$ plume detection using this methodology is the detection limit of the satellite measurements used as input (here, the OMI TRL $\mathrm{SO}_{2}$ columns). Indeed, this analysis indicates that the minimum $\mathrm{SO}_{2}$ mass that could be reliably classified as volcanic in origin using the OMI TRL $\mathrm{SO}_{2}$ data is on the order of $400 \mathrm{t}$. The lack of a priori knowledge of volcanic $\mathrm{SO}_{2}$ plume altitude restricts the classification technique to $\mathrm{SO}_{2}$ retrievals corresponding to a single CMA, and our use of the TRL $\mathrm{SO}_{2}$ product does not imply any knowledge of $\mathrm{SO}_{2}$ altitude (which is not required for eruption detection). The use of $\mathrm{OMI} \mathrm{SO}_{2}$ products with lower noise (e.g. STL columns) or more sensitive $\mathrm{SO}_{2}$ algorithms (e.g. Li et al., 2013) would result in lower detection limits, although STL retrievals would also inhibit the detection of low-altitude or diffuse plumes. Future UV satellite instruments such as the Tropospheric Monitoring Instrument (TROPOMI; http://www.tropomi.eu/), with better spatial resolution than OMI, should also have lower $\mathrm{SO}_{2}$ detection limits. In order to resolve smaller plumes, an instrument with a higher spatial resolution would be required, but such instruments typically offer lower temporal resolution. Reduced temporal resolution would not provide the daily coverage necessary for the implementation of this technique in a global near-real-time alert system. 
Although the technique described here was designed for global detection of volcanic eruptions, it could also be adapted for regional-scale assessments. For initial investigative purposes and model training the location of analysis regions was fixed based upon the location of the known emitting source, although this method could also be implemented on a global or regional scale using a reference grid. Implementation of a gridded analysis over a wider area with the developed analysis performed within each grid cell could allow the classification both above the volcano and in adjacent regions into which plumes may have drifted. For volcanoes with frequent activity during the OMI mission (2004present), the developed method of data collection and model training could be applied. Application to a single or small cluster of volcanoes would specifically tailor the resulting output to the eruptive style of the volcano or volcanoes in question and could allow refinement of the background correction based on local conditions (e.g. avoiding other known regional $\mathrm{SO}_{2}$ sources). High frequencies of eruptions and emissions in locations such as Vanuatu or Indonesia could facilitate the training of the data and might prove effective in the monitoring of persistently degassing volcanoes.

\section{Conclusions}

Through the analysis of operational $\mathrm{OMI} \mathrm{SO}_{2}$ measurements (TRL $\mathrm{SO}_{2}$ columns) for 79 volcanic eruptions, a simple logistic regression model allowed classification of volcanic from non-volcanic control events with an accuracy of $80 \%$. Optimisation of the model by progressive removal of input data enabled volcanic plumes containing at least $\sim 400 \mathrm{t}$ of $\mathrm{SO}_{2}$ to be consistently resolved and correctly classified. With an appropriate training dataset, this technique could form the basis of a near-real-time volcanic eruption detection scheme, with minimal user input necessary.

We identified some common factors resulting in misclassification of control or volcanic events, including contamination of the background analysis region with $\mathrm{SO}_{2}$ emissions from another volcano, low $\mathrm{SO}_{2}$ emissions and/or low plume altitude (i.e. resulting in emissions below detection limits), advection of $\mathrm{SO}_{2}$ emissions out of the analysis region prior to the satellite overpass, and data gaps.

The implementation of a NRT volcanic eruption alert system based on the technique described here would represent an advance in small eruption identification over current systems, such as SACS, which use a simple threshold $\mathrm{SO}_{2}$ column amount to identify significant volcanic degassing events (Brenot et al., 2014). In dispersed volcanic clouds, $\mathrm{SO}_{2}$ column amounts may be low, yet the total $\mathrm{SO}_{2}$ loading could be high; hence alerts based on $\mathrm{SO}_{2}$ mass rather than column amount may be more effective in certain situations. Development of this technique within a global or regional grid system would be effective at identifying drifting volcanic clouds far from the source, which is a current limitation. A combination of both the developed technique and existing $\mathrm{SO}_{2}$ thresh- old approaches would likely yield an optimal NRT volcanic cloud detection system suitable for both large drifting plumes and smaller eruptions.

\section{Data availability}

OMI Level 2 total column $\mathrm{SO}_{2}$ (OMSO2) data are publicly available from NASA Goddard Earth Sciences Data and Information Services Center (NASA GES DISC, 2016; http://disc.sci.gsfc.nasa.gov/Aura/data-holdings/OMI/ omso2_v003.shtml). The OMI processing code used to analyse this data (OMIplot) is available from the Vhub (2016) website (https://vhub.org/resources/682).

Acknowledgements. We acknowledge NASA for supporting this work through the Aura Science Team project (grant NNX11AF42G to Simon A. Carn) and an Earth and Space Science Fellowship to Verity J. B. Flower (NNX14AK94H).

Edited by: B. N. Duncan

Reviewed by: two anonymous referees

\section{References}

Brenot, H., Theys, N., Clarisse, L., van Geffen, J., van Gent, J., Van Roozendael, M., van der A, R., Hurtmans, D., Coheur, P.-F., Clerbaux, C., Valks, P., Hedelt, P., Prata, F., Rasson, O., Sievers, K., and Zehner, C.: Support to Aviation Control Service (SACS): an online service for near-real-time satellite monitoring of volcanic plumes, Nat. Hazards Earth Syst. Sci., 14, 1099-1123, doi:10.5194/nhess-14-1099-2014, 2014.

Carn, S. A. and Prata, F. J.: Satellite-based constraints on explosive $\mathrm{SO}_{2}$ release from Soufrière Hills Volcano, Montserrat, Geophys. Res. Lett., 37, doi:10.1029/2010GL044971, 2010.

Carn, S. A., Krueger, A. J., Bluth, G. J. S., Schaefer, S. J., Krotkov, N. A., Watson, I. M., and Datta, S.: Volcanic eruption detection by the Total Ozone Mapping Spectrometer (TOMS) instruments: A 22-year record of sulphur dioxide and ash emissions, Geological Society, London, Special Publications, 213, 177-202, 2003.

Carn, S. A., Krueger, A. J., Krotkov, N. A., Yang, K., and Levelt, P. F.: Sulfur dioxide emissions from Peruvian copper smelters detected by the Ozone Monitoring Instrument, Geophys. Res. Lett., 34, doi:10.1029/2006GL029020, 2007.

Carn, S. A., Krueger, A. J., Krotkov, N. A., Arellano, S., and Yang, K.: Daily monitoring of Ecuadorian volcanic degassing from space, J. Volcanol. Geotherm. Res., 176, 141-150, doi:10.1016/j.jvolgeores.2008.01.029, 2008.

Carn, S. A., Krotkov, N. A., Yang, K., and Krueger, A. J.: Measuring global volcanic degassing with the Ozone Monitoring Instrument (OMI), Geological Society, London, Special Publications, 380, 229-257, doi:10.1144/SP380.12, 2013.

Carn, S. A., Clarisse, L., and Prata, A. J.: Multidecadal satellite measurements of global volcanic degassing, J. Volcanol. Geotherm. Res., 311, 99-134, doi:10.1016/j.jvolgeores.2016.01.002, 2016. 
Delmelle, P., Stix, J., Baxter, P., Garcia-Alvarez, J., and Barquero, J.: Atmospheric dispersion, environmental effects and potential health hazard associated with the low-altitude gas plume of Masaya volcano, Nicaragua, B. Volcanol., 64, 423-434, 2002.

Fioletov, V. E., McLinden, C. A., Krotkov, N., Moran, M. D., and Yang, K.: Estimation of $\mathrm{SO}_{2}$ emissions using OMI retrievals, Geophys. Res. Lett., 38, L21811, doi:10.1029/2011GL049402, 2011.

Fioletov, V. E., McLinden, C. A., Krotkov, N., Yang, K., Loyola, D. G., Valks, P., Theys, N., Van Roozendael, M., Nowlan, C. R., Chance, K., and Liu, X: Application of OMI, SCIAMACHY, and GOME-2 satellite $\mathrm{SO}_{2}$ retrievals for detection of large emission sources, J. Geophys. Res.-Atmos., 118, 1139911418, doi:10.1002/jgrd.50826, 2013.

Flower, V. J. B., Carn, S. A., and Wright, R.: Impacts of sensor viewing geometry on time-series analysis of volcanic emissions, Remote Sens. Environ., 183, 282-293, doi:10.1016/j.rse.2016.05.022, 2016.

Global Volcanism Program: Volcanoes of the World, v. 4.4.3, edited by: Venzke, E., Smithsonian Institution, doi:10.5479/si.GVP.VOTW4-2013 (last access: 11 June 2016), 2013.

Haahr, M.: Random.org: True random number service, School of Computer Science and Statistics, Trinity College, Dublin, Ireland, available at: http://www.random.org, last access: June, 2015.

Hall, M., Frank, E., Holmes, G., Pfahringer, B., Reutemann, P., and Witten, I. H.: The WEKA data mining software: an update, ACM SIGKDD Explorations newsletter, 11, 10-18, 2009.

Hansell, A. und Oppenheimer, C.: Health hazards from volcanic gases: a systematic literature review, Arch. Environ. Health, 59, 628-639, 2004.

Krotkov, N. A., Carn, S. A., Krueger, A. J., Bhartia, P. K., and Yang, $\mathrm{K}$.: Band residual difference algorithm for retrieval of $\mathrm{SO}_{2}$ from the Aura Ozone Monitoring Instrument (OMI), IEEE T. Geosci. Remote, 44, 1259-1266, 2006.

Krotkov, N. A., Schoeberl, M. R., Morris, G. A., Carn, S. A., and Yang, K.: Dispersion and lifetime of the $\mathrm{SO}_{2}$ cloud from the August 2008 Kasatochi eruption, J. Geophys. Res., 115, D00L20, doi:10.1029/2010JD013984, 2010.

Krueger, A. J.: Sighting of El Chichon sulfur dioxide clouds with the Nimbus 7 total ozone mapping spectrometer, Science, 220, 1377-1379, 1983.

Krueger, A., Krotkov, N., and Carn, S.: El Chichon: The genesis of volcanic sulfur dioxide monitoring from space, J. Volcanol. Geoth. Res., 175, 408-414, 2008.

Li, C., Joiner, J., Krotkov, N. A., and Bhartia, P. K.: A fast and sensitive new satellite $\mathrm{SO}_{2}$ retrieval algorithm based on principal component analysis: Application to the ozone monitoring instrument, Geophys. Res. Lett., 40, 6314-6318, doi:10.1002/2013GL058134, 2013.

Lopez, T., Carn, S., Werner, C., Fee, D., Kelly, P., Doukas, M., Pfeffer, M., Webley, P., Cahill, C., and Schneider, D.: Evaluation of Redoubt Volcano's sulfur dioxide emissions by the Ozone Monitoring Instrument, J. Volcanol. Geoth. Res., 259, 290-307, 2013.
McCormick, B. T., Edmonds, M., Mather, T. A., and Carn, S. A.: First synoptic analysis of volcanic degassing in Papua New Guinea, Geochem. Geophy. Geosy., 13, Q03008, doi:10.1029/2011GC003945, 2012.

McCormick, B. T., Edmonds, M., Mather, T. A., Campion, R., Hayer, C. S., Thomas, H. E., and Carn, S. A.: Volcano monitoring applications of the Ozone Monitoring Instrument, Geological Society, London, Special Publications, 380, 259-291, 2013.

Miller, T. P. and Casadevall, T. J.: Volcanic ash hazards to aviation, Enc. Volcanoes, Academic Press, London, UK, 915-930, 2000.

Murphy, S. W., de Souza Filho, C. R., and Oppenheimer, C.: Monitoring volcanic thermal anomalies from space: Size matters, J. Volcanol. Geoth. Res., 203, 48-61, 2011.

NASA GES DISC: OMI Level 2 total column $\mathrm{SO}_{2}$ data, available at: http://disc.sci.gsfc.nasa.gov/Aura/data-holdings/OMI/ omso2_v003.shtml, last access: 10 November 2016.

Prata, A. J.: Satellite detection of hazardous volcanic clouds and the risk to global air traffic, Nat. Hazards, 51, 303-324, 2009.

Oommen, T., Baise, L. G., and Vogel, R.: Validation and application of empirical liquefaction models, J. Geotech. Geoenviron., 136, 1618-1633, 2010.

Oommen, T., Baise, L. G., and Vogel, R. M.: Sampling bias and class imbalance in maximum-likelihood logistic regression, Mat. Geosci., 43, 99-120, 2011.

Rodríguez, J. D., Perez, A., and Lozano, J. A.: Sensitivity analysis of $\mathrm{k}$-fold cross validation in prediction error estimation, IEEE T. Pattern. Anal., 32, 569-575, 2010.

Schneider, D. J., Dean, K., Dehn, J., Miller, T., and Kirianov, V. Y.: Monitoring and analyses of volcanic activity using remote sensing data at the Alaska Volcano Observatory: case study for Kamchatka, Russia, December 1997, Geoph. Monog. Series, 65$85,2000$.

Self, S., Zhao, J. X., Holasek, R. E., Torres, R. C., and King, A. J.: The atmospheric impact of the 1991 Mount Pinatubo eruption, US Geological Survey (USGS), 1993.

Telling, J. W, Flower, V. J. B., and Carn, S. A.: A multi-sensor satellite assessment of $\mathrm{SO}_{2}$ emissions from the 2012-13 eruption of Tolbachik volcano, Kamchatka, J. Volcanol. Geoth. Res., 307, 98-106, doi:10.1016/j.jvolgeores.2015.07.010, 2015.

VHub: OMI processing code, available at: https://vhub.org/ resources/682, last access: 10 November 2016.

Witten, I. H. and Frank, E.: Data Mining: Practical machine learning tools and techniques, Morgan Kaufmann, 119-127, 2005.

Wright, R., Flynn, L., Garbeil, H., Harris, A., and Pilger, E.: Automated volcanic eruption detection using MODIS, Remote Sens. Environ., 82, 135-155, 2002.

Wright, R., Flynn, L. P., Garbeil, H., Harris, A. J., and Pilger, E.: MODVOLC: near-real-time thermal monitoring of global volcanism, J. Volcanol. Geoth. Res., 135, 29-49, 2004.

Yang, K., Krotkov, N. A., Kruger, A. J., Carn, S. A., Bhartia, P. K., and Levelt, P. F.: Retrieval of large volcanic $\mathrm{SO}_{2}$ columns from the Aura Ozone Monitoring Instrument: comparison and limitations, J. Geophys. Res.-Atmos., 112, D24S43, doi:10.1029/2007JD008825, 2007. 